Full length article

\title{
Effect of heat waves on morbidity and mortality due to Parkinson's disease in Madrid: A time-series analysis
}

\author{
Cristina Linares a , Pablo Martinez-Martin ${ }^{\text {b }}$, Carmen Rodríguez-Blázquez ${ }^{\mathrm{b}}$, Maria João Forjaz ${ }^{\mathrm{a}, \mathrm{c}}$, \\ Rocío Carmona a , Julio Díaz ${ }^{\text {a,* }}$ \\ a National School of Public Health, Carlos III Institute of Health, Madrid, Spain \\ ${ }^{\mathrm{b}}$ National Centre of Epidemiology, Carlos III Institute of Health and CIBERNED, Madrid, Spain \\ c REDISSEC, Spain
}

\section{A R T I C L E I N F O}

\section{Article history:}

Received 28 December 2015

Received in revised form 21 January 2016

Accepted 21 January 2016

Available online 26 January 2016

\section{Keywords:}

Parkinson

Mortality

Morbidity

Heat wave

Temperature

\begin{abstract}
A B S T R A C T
Background: Parkinson's disease (PD) is one of the factors which are associated with a higher risk of mortality during heat waves. The use of certain neuroleptic medications to control some of this disease's complications would appear to be related to an increase in heat-related mortality.

Objective: To analyse the relationship and quantify the short-term effect of high temperatures during heat wave episodes in Madrid on daily mortality and PD-related hospital admissions.

Methods: We used an ecological time-series study and fit Poisson regression models. We analysed the daily number of deaths due to PD and the number of daily PD-related emergency hospital admissions in the city of Madrid, using maximum daily temperature $\left({ }^{\circ} \mathrm{C}\right)$ as the main environmental variable and chemical air pollution as covariates. We controlled for trend, seasonalities, and the autoregressive nature of the series.

Results: There was a maximum daily temperature of $30{ }^{\circ} \mathrm{C}$ at which PD-related admissions were at a minimum. Similarly, a temperature of $34{ }^{\circ} \mathrm{C}$ coincides with an increase in the number of admissions. For PD-related admissions, the Relative Risk (RR) for every increase of $1{ }^{\circ} \mathrm{C}$ above the threshold temperature was 1.13 IC95\%:(1.031.23) at lags 1 and 5; and for daily PD-related mortality, the RR was 1.14 IC95\%:(1.01-1.28) at lag 3.

Conclusion: Our results indicate that suffering from PD is a risk factor that contributes to the excess morbidity and mortality associated with high temperatures, and is relevant from the standpoint of public health prevention plans.
\end{abstract}

(c) 2016 Elsevier Ltd. All rights reserved.

\section{Introduction}

Parkinson's disease (PD) is the second leading degenerative disease in the population and entails a high economic cost, particularly at advanced stages of the disease (Rodríguez-Blázquez et al., 2015; Reese et al., 2012; Mateus and Coloma, 2013). Suffering from a neurodegenerative disorder such as PD is one of the factors which, at an individual level, are associated with a higher risk of mortality during heat waves (Ministerio Sanidad Servicios Sociales e Igualdad, 2015). Moreover, the use of certain neuroleptic medications to control some of this disease's complications would appear to be related to an increase in heat-related mortality, as indeed occurred in the heat wave in France in 2003 (Stöllberger and Finsterer, 2007). Suffering from PD is thus a risk factor that contributes to the excess morbidity and mortality associated with high temperatures, and is relevant for public health prevention purposes.

\footnotetext{
* Corresponding author at: Escuela Nacional de Sanidad, Instituto de Salud Carlos III, Monforte de Lemos, 5. 28029, Madrid, Spain.

E-mail address: j.diaz@isciii.es (J. Díaz).
}

From an environmental stance, some risk factors have been linked to development of PD, with pesticides (herbicides, insecticides, and fungicides) being the pre-eminent agents. Certain occupations (farming, welding, mining, painting) and circumstances (e.g., rural lifestyle, well-water use) have been related to an increased risk of suffering from PD, possibly associated with exposure to paraquat, rotenone, maneb, metals such as iron and manganese, organic solvents, or other products that are potentially toxic for the central nervous system and, specifically, for the substantia nigra. These agents presumably act by causing oxidative stress, inflammation, mytochondrial dysfunction, inhibition of proteasome and other disorders which culminate in cell death (Wirdefeldt et al., 2011; Campdelacreu, 2014; Agim and Cannon, 2015). Nevertheless, the evidence supporting such proposals is limited or inconsistent, and until now, only MPTP (1-methyl-4phenyl-1,2,3,6-tetrahydropyridine) has been shown to give rise to a PD-like disorder in the human being (Baltazar et al., 2014; Kieburtz and Wunderle, 2013; Chin-Chan et al., 2015).

Recently, there has been a shift in the approach taken to the participation of certain environmental factors in the aetiology of PD (and of other neurodegenerative diseases, such as Alzheimer's disease). 
According to this, it is not merely that exposure to environmental factors affects a selected population sample such as workers and the above-described population groups, but rather that factors to which the entire population is exposed, such as traffic-related air pollution (Ritz et al., 2015), are related to the aetiology or exacerbation of neurodegenerative diseases.

As regards the effect of high temperatures on PD, it is not suggested that high temperatures are related to a higher prevalence of the disease by participating in its aetiology. Instead, it is argued that -whether by virtue of a biological mechanism such as dopamine deficit linked to hyperthermia in heat waves (Finsterer et al., 2011) or by virtue of the effect of neuroleptic use during heat waves on persons over the age of 70 years (Stöllberger and Finsterer, 2007)- the effect of high temperatures may translate as disease exacerbations, which in turn have an impact on traditional health indicators, such as daily mortality or hospital admissions. Accordingly, the aim of this study was to establish the link between and quantify the short-term effect of high temperatures during heat waves in Madrid on daily PD-related mortality and hospital admissions. We conducted a novel analysis in this area of research, by means of an ecological time-series study. This study is especially pertinent, bearing in mind that the over-75 age group, in which the highest PD incidence is found (Huse et al., 2005), is also the age group to which the highest heat-wave mortality is attributed in Madrid (Díaz et al., 2015a), and that this is an environmental risk which, in the context of climate change, is destined to become ever more frequent and more intense (IPCC, 2014).

\section{Methods}

\subsection{Study population}

The city of Madrid is a densely populated metropolitan area situated in the central region of Spain. In the period 2001-2009, it had a mean population of 3,116,897 and of this total, 284,929 persons (9\%) were aged 75 years or over (INE, 2014).

\subsection{Outcomes}

The following two data sources were used to obtain the main variables of analysis:

- Number of daily deaths due to PD (International Classification of Diseases 10th Revision (ICD-10); (ICD-10: G20-G21) in the city of Madrid from 01 to 01-2001 to 31-12-2009, based on data furnished by the National Statistics Institute to the Carlos III Institute of Health (Ministry of Economic Affairs \& Competitiveness/Ministerio de Economía and Competitividad), for the purpose of undertaking a "Study of influenza-related mortality in Spain".

- Number of daily PD-related emergency admissions (ICD-10: G20-G21) to municipal hospitals in Madrid from 01 to 01-2008 to 31-12-2009, obtained from the Minimum Basic Data Set (MBDS) (Conjunto Mínimo Básico de Datos) compiled by the Ministry of Health, Social Services \& Equality.

\subsection{Exposure}

As the main environmental variable in the analysis we used maximum daily temperature $\left({ }^{\circ} \mathrm{C}\right)$, since it displays the closest relationship with heat-wave-related morbidity and mortality in Spain (Díaz et al., 2015b). The maximum daily temperature data for the above time periods correspond to readings taken at the Madrid Retiro observatory, situated in the centre of the city of Madrid, and were furnished by the State Meteorological Agency (Agencia Estatal de Meteorología/AEMET).

To assess whether there was a functional relationship between maximum daily temperature and PD, and if so of what type, we plotted scatterplot diagrams. These diagrams furnish information on the type of relationship that exists (linear or otherwise) between mortality, hospital admissions and maximum temperature during the period analysed. In these diagrams, the value of mortality or the value of PDrelated admissions corresponds to the mean value taken by this variable for each $2{ }^{\circ} \mathrm{C}$ interval between the minimum and maximum values of maximum temperature. If, as generally happens with all-cause morbidity and mortality (Díaz et al., 2002; Linares and Díaz, 2008), there is a temperature point above which the dependent variable analysed increases, this is called the "Threshold temperature (Tthreshold)" and is calculated by linear-type adjustment with loess smoothing. In the process of modelling and quantification of risk, the non-linear character of this maximum temperature-PD relationship is then taken into account as follows:

$$
\begin{aligned}
& \mathrm{T}_{\text {cal }}=0 \quad \text { if } \mathrm{T}_{\max }<\text { Tthreshold } \\
& \mathrm{T}_{\text {cal }}=\mathrm{T}_{\max }-\text { Tthreshold } \quad \text { if } \mathrm{T}_{\max }>\text { Tthreshold }
\end{aligned}
$$

where Tcal is the variable that determines the existence of the effect of a heat wave on PD-related morbidity and mortality. Given that the effect of a heat wave on PD may not be immediate, the following lagged variables were calculated: $\mathrm{T}_{\text {cal }}$ ( $\operatorname{lag} 1$ ), which takes into account the effect of the temperature on day " $d$ " on mortality, one day later, " $d+1$ "; $\mathrm{T}_{\text {cal }}$ (lag 2 ), which takes into account the effect of the temperature on day "d" on mortality, two days later, " $\mathrm{d}+2$ "; and so on successively. The number of lags were selected on the basis of the literature, which establishes that the effect of heat on total mortality is short-term ( $T_{\text {cal }}$ : lags 1-5) (Alberdi et al., 1998).

\subsection{Covariates}

\subsubsection{Other meteorological variables}

In addition, we considered the mean daily air pressure ( $\mathrm{Pa}$ ) and mean daily relative humidity $(\mathrm{Hr})$ corresponding to the same study period, as recorded at the Madrid-Retiro observatory and furnished by AEMET. Previous studies conducted in Madrid have already shown the influence of these meteorological parameters on all-cause morbidity and mortality both in heat and in cold waves (González et al., 2001; Díaz et al., 2002).

\subsubsection{Variables of chemical air pollution}

Based on previous studies on $\mathrm{PM}_{10}, \mathrm{PM}_{2.5}$ and $\mathrm{NO}_{2}$ (Jiménez et al., 2009), the relationship with morbidity and mortality was assumed to be linear, with the effect on the latter being felt until lag 5 , with the corresponding lagged variables being created until this lag in the same way as for temperature. In the case of ozone $\left(\mathrm{O}_{3}\right)$, the functional relationship obtained by other studies was quadratic (Díaz et al., 1999) with an effect felt as far as lag 9. We worked with mean daily concentrations $\left(\mu \mathrm{g} / \mathrm{m}^{3}\right)$, obtained as the overall mean value for the grid of stations which routinely measure chemical air pollution in Madrid. The data were supplied by the Madrid Municipal Air Pollution Monitoring Grid (Red de Vigilancia de la Contaminación Atmosférica del Ayuntamiento de Madrid).

\subsubsection{Other control variables}

In addition to the above-mentioned variables, we also controlled for trend, annual, six-monthly and weekly seasonalities, the autoregressive nature of the series, and days of the week.

\subsection{Statistical analysis}

To calculate the impact of heat waves on PD-related morbidity and mortality, generalised linear models (GLMs) were constructed with the Poisson regression link. This made it possible to obtain the estimator to calculate the relative risk (RR) of both daily mortality and nonemergency hospital PD admissions associated with an increase of $1{ }^{\circ} \mathrm{C}$ 
above the Tthreshold. Based on the RR, we then calculated the attributable risk (AR) associated with this increase via the following equation: $A R=R R-1 / R R$ (Coste and Spira, 1991). Significant environmental variables were determined using the Step-Step procedure, beginning with the model that included all the explanatory variables, and gradually eliminating those which individually displayed least statistical significance, with the process being reiterated until all the variables included were significant at $p<0.05$.

All analyses were performed using the IBM SPSS Statistics 22 and STATA v 11.2 statistical software programmes.

\section{Results}

Table 1 shows the descriptive statistics for PD-related mortality, maximum daily temperature and the environmental control variables across the period 2001-2009. Observations of $\mathrm{PM}_{2.5}$ are lower than those of other air pollutants because $\mathrm{PM}_{2.5}$ concentrations do not begin to measure up to the year 2004 in Madrid. In the period analysed the WHO air quality guidelines for $\mathrm{PM}_{2.5}$ have exceeded 329 times (10.0\%) and for $\mathrm{PM}_{10} 446$ times (13.6\%).For $\mathrm{NO}_{2}$ values, the $\mathrm{WHO}$ guidelines are for annual means, for this pollutant the value has been surpassed all of the years in the period analysed. For $\mathrm{O}_{3}$ values, the WHO air quality guidelines are for 8-h concentrations. In our analysis, the measurements of $\mathrm{O}_{3}$ were daily means concentrations. Similarly, Table 2 shows the descriptive statistics for PD-related hospital admissions and the independent and control variables across the period 2008-2009. The WHO air quality guidelines for PM2.5 have exceeded 29 times (4.0\%) and for PM10 28 times (3.8\%). These values indicate that air quality in Madrid has improved in the years analysed.

Fig. 1 shows the scatterplot diagram depicting PD-related hospital admissions by reference to maximum daily temperature, for temperatures above $20^{\circ} \mathrm{C}$, with a percentage of loess fit of $75 \%$. As can be seen from the figure, there was a maximum daily temperature of around $30{ }^{\circ} \mathrm{C}$ at which PD-related admissions fell to a minimum. It will likewise be seen that there was a temperature of around $34{ }^{\circ} \mathrm{C}$ above which the number of admissions due to this disease increased most steeply. This temperature of $34{ }^{\circ} \mathrm{C}$ was thus the one used in study to define "heat wave" and quantify the effect of maximum daily temperature during heat waves on PD-related admissions. For study purposes, therefore, a heat wave in Madrid was defined as any day on which the maximum daily temperature exceeded $34^{\circ} \mathrm{C}$. In the case of PD-related mortality, this functional relationship was not observed. The PD mortality is very scarce, its mean value is 0.3 with a range of $0-4$; these values do not permit to obtain a scatter plot similar to Fig. 1.

On the basis of this criterion, during the period 2001-2009 there were 198 days on which the threshold of $34{ }^{\circ} \mathrm{C}$ was exceeded, with a mean exceedance value of $1.54{ }^{\circ} \mathrm{C}$, whereas in the period 2008-2009 there were 59 such days with a mean exceedance value of $1.63^{\circ} \mathrm{C}$.

Table 3 shows the results of modelling and quantifying risk via the $\mathrm{RR}$ and AR for each degree that the maximum daily temperature exceeded the threshold of $34^{\circ} \mathrm{C}$, and the lags between the increase in temperature and its effect on the variables of interest. It can be observed that the RR and AR were very similar both for PD-related hospital

Table 1

Descriptive statistics of daily mortality due to Parkinson's disease (PD) and independent and control variables: Madrid, 2001-2009.

\begin{tabular}{lcclrr}
\hline & $\mathrm{N}$ & Maximum & Minimum & Mean & $\begin{array}{c}\text { Standard } \\
\text { deviation }\end{array}$ \\
\hline Daily PD-related mortality & 3287 & 4 & 0 & 0.3 & 0.6 \\
$\mathrm{Tmax}\left({ }^{\circ} \mathrm{C}\right)$ & 3287 & 38.6 & 1.0 & 20.2 & 8.7 \\
$\mathrm{NO}_{2}\left(\mu \mathrm{g} / \mathrm{m}^{3}\right)$ & 3287 & 142.0 & 0 & 59.4 & 17.9 \\
$\mathrm{PM}_{2,5}\left(\mu \mathrm{g} / \mathrm{m}^{3}\right)$ & 2192 & 71.4 & 3.4 & 17.1 & 7.8 \\
$\mathrm{PM}_{10}\left(\mu \mathrm{g} / \mathrm{m}^{3}\right)$ & 3287 & 149.0 & 0 & 32.5 & 16.1 \\
$\mathrm{O}_{3}\left(\mu \mathrm{g} / \mathrm{m}^{3}\right)$ & 3287 & 89.4 & 0 & 35.7 & 18.1 \\
\hline
\end{tabular}

Table 2

Descriptive statistics of daily hospital admissions due to Parkinson's disease (PD) and independent and control variables: Madrid, 2008-2009.

\begin{tabular}{lcrrrr}
\hline & $\mathrm{N}$ & Maximum & Minimum & Mean $\begin{array}{c}\text { Standard } \\
\text { deviation }\end{array}$ \\
\hline $\begin{array}{l}\text { Daily PD-related hospital } \\
\quad \text { admissions }\end{array}$ & 731 & \multicolumn{1}{c}{25} & 0 & 9.2 & 3.7 \\
$\mathrm{Tmax}\left({ }^{\circ} \mathrm{C}\right)$ & 731 & 38.4 & 1.0 & 20.5 & 8.9 \\
$\mathrm{NO}_{2}\left(\mu \mathrm{g} / \mathrm{m}^{3}\right)$ & 731 & 121.0 & 17.6 & 54.9 & 17.3 \\
$\mathrm{PM}_{2,5}\left(\mu \mathrm{g} / \mathrm{m}^{3}\right)$ & 731 & 41.9 & 3.4 & 13.6 & 5.5 \\
$\mathrm{PM}_{10}\left(\mu \mathrm{g} / \mathrm{m}^{3}\right)$ & 731 & 105.0 & 6.9 & 25.4 & 11.6 \\
$\mathrm{O}_{3}\left(\mu \mathrm{g} / \mathrm{m}^{3}\right)$ & 731 & 88.8 & 6.7 & 41.7 & 19.0 \\
\hline
\end{tabular}

admissions and for daily mortality due to this cause. The values of AR observed in Table 3, indicate that for daily PD-related mortality for every degree above $34{ }^{\circ} \mathrm{C}$ there was an increase of $12.11 \%$ and similarly, for daily PD-related hospital admissions there was an increase of $11.47 \%$. As the mean exceedance value was $1.54{ }^{\circ} \mathrm{C}$ in heat wave in the period 2001-2009, increased PD-related mortality was $18.6 \%$ in the days of heat wave. Resulting in 11 PD- deaths attributed to heat in that period. In the same way, the hospital admissions due to PD attributable to heat in the period 2008-2009 were 101.

\section{Discussion}

The results of the time series analysis show that there is a short-term effect of high temperatures on the daily mortality and hospital admissions due to PD during the heat waves in Madrid.

Specifically, in Table 1 attention should be drawn to the low daily PD-related mortality in relation to the number of emergency hospital admissions due to this disease, as well as the small standard deviation. In all likelihood, the low number of PD-related deaths is the reason why there is no $\mathrm{V}$-shaped relationship in evidence between maximum daily temperature and PD-related mortality in the scatterplot diagram.

The functional form obtained in Fig. 1 is very similar to that found by another study which analysed all-cause hospital admissions according to maximum daily temperature in Madrid across the period 19952000 (Linares and Díaz, 2008). In that instance, the temperature taken as the heat wave definition threshold was $36{ }^{\circ} \mathrm{C}$, a very similar figure to that found for all-cause mortality, $36.5^{\circ} \mathrm{C}$, based on data for the period 1986-1997 (Díaz et al., 2002). This decline coincides with that seen for the heat wave definition in Madrid, which was also set, for this period 2001-2009, at $34^{\circ} \mathrm{C}$ (Díaz et al., 2015b), as a consequence of the ageing of the Madrid metropolitan population, in which the over-75 age segment rose from 7.3\% in 1986-1997 to 9.8\% in 2009 (INE, 2014).

Another noteworthy finding was that there might be a minimum PD-related admissions temperature that is close to a maximum daily temperature of $29^{\circ} \mathrm{C}$. Once again, this would be in line with the pattern of all-cause mortality across the period 1986-1997, in which a minimum mortality temperature in Madrid was calculated and set at a maximum daily temperature of $30.8^{\circ} \mathrm{C}$, i.e., there was a fall of almost $2{ }^{\circ} \mathrm{C}$ in this temperature. Although recent research indicates that in recent decades the minimum mortality temperature in Stockholm has displayed an upward trend as a consequence of the population's acclimatisation to heat (Åström et al., 2015), in the case of Madrid, as in other Spanish regions (Mirón et al., 2008, Díaz et al., 2015b), the relative weight of population ageing is greater than that of adaptation to heat, and the trend in the minimum mortality or heat wave threshold temperature is therefore downward. It is likewise noteworthy that, with respect to temperature, the relationship between PD and mortality displays a very similar pattern to that observed for all-cause morbidity and mortality. The reason is probably that in the case of heat wave mortality in Madrid, the age group that registers the highest daily attributable mortality is the over75 segment (Díaz et al., 2015a), similar to what is seen in PD-related morbidity and mortality. 


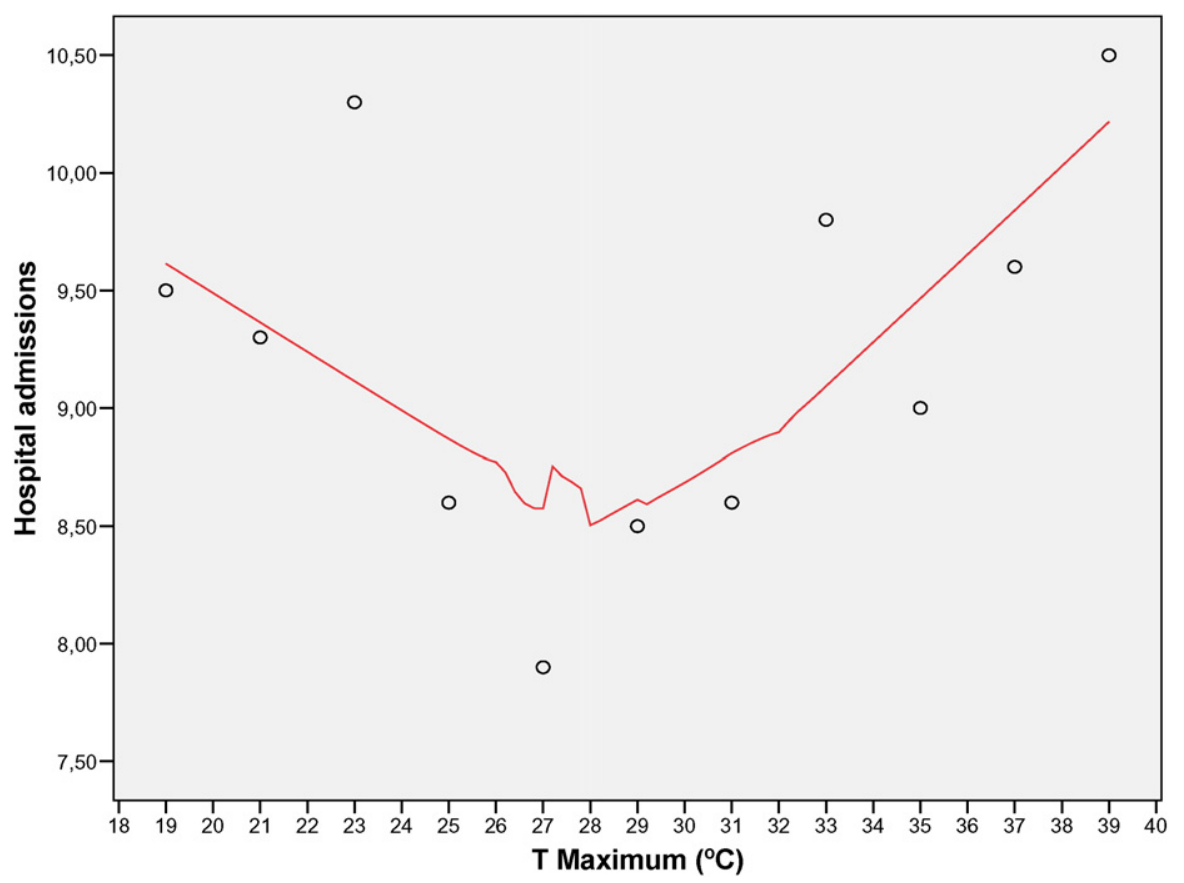

Fig. 1. Functional relationship between admissions due to Parkinson's disease and maximum daily temperature.

Our study design, i.e., a longitudinal, ecological time-series analysis, has novel features with respect to the methodology used in the few studies that analyse the relationship between environmental factors and PD (Chin-Chan et al., 2015; Ritz et al., 2015). In the latter, exposure to the environmental factor, generally traffic-related pollution, remains constant throughout the study period, something that acts as a bar to detecting the temporal effect of the incidence of the pollutant on PD. This is the appropriate methodology if the aim is to show the relationship between the disease and a possible environmental origin. When it comes to demonstrating that the short-term effect of a given environmental factor can exacerbate the symptoms of this disease, however, time-series analysis shows itself to be especially useful, since it enables one to establish the time window between the cause (increase in temperature) and the effect (increase in PD-related morbidity and mortality). In the sense of exacerbation of specific health events, this methodology has shown its utility in other previous studies, such as the study of adverse birth outcomes and traffic noise (Díaz and Linares, 2015) and $\mathrm{PM}_{2.5}$ concentrations and heat-wave temperatures (Arroyo et al., 2016).

As mentioned above, there are two mechanisms that can account for the effect found between temperature and PD-related morbidity and mortality in Madrid: on the one hand, those related to the disease per se and, on the other, those related to the antiparkinson medication.

A relatively frequent feature of PD are disorders in the regulation of body temperature and the presence of dyshidrosis (hyperhidrosis, hypohidrosis), which may be present in as many as 30\%-65\% of cases (Swinn et al., 2003; Hirayama, 2006). Their genesis has been attributed to both central (e.g., hypothalamic or vagal dysfunction) and peripheral (postganglionic dysfunction in advanced disease) mechanisms and to a

Table 3

Relative risk (RR) and attributable risk (AR) for each ${ }^{\circ} \mathrm{C}$ that the maximum daily temperature exceeded the threshold of $34^{\circ} \mathrm{C}$. Significance of variables at $p<0.05$.

\begin{tabular}{lll}
\hline & RR (95\% CI) & AR (95\% CI) \\
\hline Daily PD-related $^{\text {a }}$ mortality (lag 3) & $1.14(1.011 .28)$ & $12.11 \%(0.9322 .03)$ \\
$\begin{array}{l}\text { Daily PD-related hospital admissions (lag } \\
\quad 1 \text { lag 5) }\end{array}$ & $1.13(1.031 .23)$ & $11.47 \%(3.3218 .90)$ \\
\hline
\end{tabular}

a PD: Parkinson's disease. variable relationship with other symptoms of autonomic dysfunction, fluctuations and dyskinaesias (e.g., hyperhidrosis during off-phases, or during "on-phases with dyskinaesias") (Schestatsky et al., 2006; Pursiainen et al., 2007).

Insofar as the effects of antiparkinson medication are concerned, these are variable, with the triggering of and improvement in dyshidrosis and the absence of effect all having been reported in the case of dopaminergic drugs (Swinn et al., 2003; Hirayama, 2006). Cases of heat stroke have been described in PD patients, attributable to mobility or cognitive problems in avoiding high temperatures, dyshidrosis, medication, and even altered expression of 'heat-shock' protein due to conformational anomalies (Yamashita et al., 2012). It has recently been reported that the presence of delirium and fever in patients with PD and indications of systemic inflammation (leukocytosis and increased plasma C-reactive protein) might be risk factors for a subacute and prolonged deterioration in motor deficit (Umemura et al., 2014).

Furthermore, the response times observed between the cause (increase in temperature) and the effect on PD-related mortality are in line with the above-described biological mechanisms and with other studies that analyse the effect of heat on mortality. In recent studies undertaken in the city of Madrid (Linares et al., 2014), the effect of temperature on mortality in the 75-year age group has been observed to have an immediate effect (lag 0 ) and another more lagged effect (lag 3). In the case of PD-related mortality, this immediate effect was not detected, perhaps because the acute nature of heat-related mortality was mainly related to cardiovascular diseases (Alberdi et al., 1998), with the disorders with less immediate outcomes, such as respiratory diseases (Díaz et al., 2002) and, in this case, mortality due to PD, being those that contribute to the effect of heat on mortality at subsequent lags (lag 3).

In the case of hospital admissions, lags 1 and 5 at which associations were found are in line, not only with processes of almost immediate exacerbation of PD which entail the patient being admitted to hospital (lag 1 ), but also with longer-term processes related to the disease per se and the taking of medications (Stöllberger and Finsterer, 2007), all of which has the effect of increasing the lag in respect of PD admissions (lag 5).

The magnitude of the association found for PD-related mortality, with an AR of $12.11 \%$ (0.93 22.03), was greater than that observed for heat-related all-cause mortality across all age groups in Madrid for 
this same period, with an AR of 6.7\% (5.4 7.0) (Díaz et al., 2015b). Similarly, the AR associated with PD-related mortality was higher than that found for all causes among persons over the age of 75 years, namely, 5.4\% (2.1 8.7) (Linares et al., 2014). The low daily PD-related mortality may be the cause of this higher AR for heat-related mortality as well as the width of the confidence interval, which accounts for the fact that the above differences were not statistically significant.

As regards the quantification of the effect observed between PDrelated hospital admissions and maximum daily temperature in heat waves, with an AR of $11.5 \%$ (3.3 19.0), only one study has been undertaken in the city of Madrid on emergency hospital admissions during heat waves (Linares and Díaz, 2008), though the time periods do not coincide (the latter study covered the period 1995-2000) and the heat wave definition threshold has also changed (it was previously $36{ }^{\circ} \mathrm{C}$ ). Taking these facts into account, the effect found for heat-related allcause hospital admissions among persons over the age of 75 years ((17.9\% (9.5 26.0)) was slightly greater than that found for PD-related admissions ((11.5\% (3.32 18.9)), though the difference was not statistically significant. Comparison by specific causes, however, indicates that the effect for PD was greater than that observed for heat-related circulatory causes, in which there was no effect on admissions due to the fact that persons died before reaching hospital (Mastrangelo et al., 2006, Kovats et al., 2004), and smaller than that observed for respiratory causes, 27.5 (13.3-41.4) (Linares and Díaz, 2008).

With respect to the limitations of this study and any possible resulting biases, the following should be mentioned: firstly, in the case of an ecological study such as ours, does not permit inferences to be made at the level of individuals, for fear of the ecological fallacy arising as a result of the use of pooled data. Furthermore, when it comes to methodological limitations, mention should essentially be made of two shortcomings inherent in a statistical method which works with a high number of variables at a 95\% confidence level. On the other hand, an acknowledged limitation of all studies of ambient data is that measurements from stationary outdoors monitors may not represent individual exposure, although relatively crude, ambient measures are often the most feasible measure of exposure in terms of cost and burden to the study participant (Samet et al., 2000). No specific validation was done within the project to assess representativeness of spatial variability in air pollutants, our study suffered from Berkson-type measurement error, between others bias associated to an ecological exposure, as is common in most time-series studies of air pollution, which leads to no or little bias but decreases statistically power. The concentrations of air pollutants have different spatial distributions, and how well outdoor levels reflect indoor levels also varies. This leads to different degrees of measurement error-and therefore of power- for each of them, and this may influence which associations are detected.

In conclusion, it should be stressed that time-series analysis methodology made it possible to establish the existence of a quantifiable relationship between high temperatures during heat waves and PDrelated morbidity and mortality in Madrid. This result is particularly relevant, bearing in mind, on the one hand, that population ageing in developed countries means that these types of disease are going to increase over time, and on the other, that heat waves are going to become ever more frequent and more intense (IPCC, 2014). The establishment of time lags between increases in temperature and hospital admissions due to this disease may well prove extremely useful for public health in general, and for health-service management in particular. For example, patients with PD could be considered as a vulnerable group when there are heat waves, for which preventive measures would be especially important. Similar studies should thus be conducted on a multi-city scale to lend robustness to the results obtained.

\section{Acknowledgements}

This study was funded by a "Miguel Servet Type 1" grant: SEPY 1037/ 14 and a FIS Project ENPY 1001/13 from the Carlos III Institute of Health.

\section{References}

Agim, Z.S., Cannon, J.R., 2015. Dietary factors in the etiology of Parkinson's disease. Biomed. Res. Int. 2015, 672838

Alberdi, J.C., Diaz, J., Montero, J.C., Miron, I., 1998. Daily mortality in Madrid community 1986-1992: relationship with meteorological variables. Eur. J. Epidemiol. 14, 571-578.

Arroyo, V., Díaz, J., Ortíz, C., Carmona, R., Sáez, M., Linares, C., 2016. Short term effect of air pollution, noise and heat waves on preterm births in Madrid (Spain). Environ. Res $145,162-168$.

Åström, D.O., Tornevi, A., Ebi, K.L., Rocklöv, J., Forsberg, B., 2015. Evolution of minimum mortality temperature in Stockholm, Sweden, 1901-2009. Environ. Health Perspect. http://dx.doi.org/10.1289/ehp.1509692.

Baltazar, M.T., Dinis-Oliveira, R.J., de Lourdes, B.M., Tsatsakis, A.M., Duarte, J.A., Carvalho, F., 2014. Pesticides exposure as etiological factors of Parkinson's disease and other neurodegenerative diseases-a mechanistic approach. Toxicol. Lett. 230 (2), 85-103.

Campdelacreu, J., 2014. Parkinson disease and Alzheimer disease: environmental risk factors. Neurologia 29 (9), 541-549.

Chin-Chan, M., Navarro-Yepes, J., Quintanilla-Vega, B., 2015 Apr 10. Environmental pollutants as risk factors for neurodegenerative disorders: Alzheimer and Parkinson diseases. Front Cell Neurosci. 9, 124. http://dx.doi.org/10.3389/fncel.2015.00124.

Coste, J., Spira, A., 1991. Le proportion de cas attributable en Santé Publique: definition(s), estimation(s) et interpretation. Rev. Epidemiol. Sante Publique 51, 399-411.

Díaz, J., Linares, C., 2015. Traffic noise and adverse birth outcomes in Madrid: A timeseries analysis. Epidemiology http://dx.doi.org/10.1097/EDE.0000000000000406.

Díaz, J., García, R., Ribera, P., Alberdi, J.C., Hernández, E., Pajares, M.S., 1999. Modeling of air pollution and its relationship with mortality and morbidity in Madrid (Spain). Int. Arch. Occup. Environ. Health 72, 366-376.

Díaz, J., Jordán, A., García, R., Hernández, E., López, C., Otero, A., 2002. Heat waves in Madrid 1986-1997: effects on the health of the elderly. Int. Arch. Occup. Environ. Health $75,163-170$

Díaz, J., Carmona, R., Mirón, I.J., Ortiz, C., Linares, C., 2015a. Comparison of the effects of extreme temperatures on daily mortality in Madrid (Spain), by age group: the need for a cold wave prevention plan. Environ. Res. 143, 186-191.

Díaz, J., Carmona, R., Mirón, I.J., Ortiz, C., León, I., Linares, C., 2015b. Geographical variation in relative risks associated with heat: update of Spain's heat wave prevention plan. Environ. Int. 85, 273-283.

Finsterer, J., Reining-Festa, A., Stollbergr, C., Voigtlander, T., 2011. Dopamine-deficiencyenhanced hyperthermia and rhabdomyolysis during a heat wave in a metachromatic leucodystrophy heterozygote with metabolic myopathy. Acta Neurol. Belg. 111, 321-324.

González, S., Díaz, J., Pajares, M.S., Alberdi, J.C., López, C., Otero, A., 2001. Relationship between atmospheric pressure and mortality in the Madrid Autonomous Region: a time series study. Int. J. Biometeorol. 45, 34-40.

Hirayama, M., 2006. Sweating dysfunctions in Parkinson's disease. J. Neurol. 253, VII42-VII47.

Huse, D.M., Schulman, K., Orsini, L., Castelli-Haley, J., Kennedy, S., Lenhart, G., 2005. Burden of illness in Parkinson's disease. Mov. Disord. 20, 1449-1454.

INE 2014. Cifras de Población A 1 de Enero de 2014. Movimiento Natural de la Población. Fenómenos Demográficos INE (http://www.ine.es/).

IPCC 2014: Climate Change 2014: Synthesis Report. Contribution of Working Groups I, II and III to the Fifth Assessment Report of the Intergovernmental Panel on Climate Change [Core Writing Team, R.K. Pachauri and L.A. Meyer (eds.)]. IPCC, Geneva, Switzerland, $151 \mathrm{pp}$.

Jiménez, E., Linares, C., Rodríguez, L.F., Bleda, M.J., Díaz, J., 2009. Short-term impact of particulate matter $\left(\mathrm{PM}_{2.5}\right)$ on daily mortality among the over-75 age group in Madrid (Spain). Sci. Total Environ. 407, 5486-5492.

Kieburtz, K., Wunderle, K.B., 2013. Parkinson's disease: evidence for environmental risk factors. Mov. Disord. 28 (1), 8-13.

Kovats, R.S., Hajat, S., Wilkinson, P., 2004. Contrasting patterns of mortality and hospital admissions during the hot weather and heat waves in Greater London, UK. Occup. Environ. Med. 61, 893-898.

Linares, C., Díaz, J., 2008. Impact of high temperatures on hospital admissions: comparative analysis with previous studies about mortality (Madrid). Eur. J. Pub. Health 18, 318-322.

Linares, C., Carmona, R., Díaz, J., 2014. Análisis del impacto a corto plazo de los extremos térmicos y de otros factores environmental sobre la mortalidad diaria en la ciudad de Madrid en el periodo 2001-2009. Reports I and II Prepared for the European Commission Under the BASE (Bottom-UP Climate Adaptation Strategies Towards a Sustainable Europe) Project, 7th Research Framework Programme Under GA. 308, p. 337.

Mastrangelo, G., Hajat, S., Fadda, E., et al., 2006. Contrasting patterns of hospital admissions and mortality during heat waves: are deaths from circulatory disease a real excess or an artifact? Med. Hypotheses 66, 1025-1028.

Mateus, C., Coloma, J., 2013. Health economics and cost of illness in Parkinson's disease. Eur. Neurol. Rev. 8 (1), 6-9.

Ministerio Sanidad Servicios Sociales e Igualdad, 2015. http://www.msssi.gob.es/ ciudadanos/saludAmbLaboral/planAltasTemp/2015/docs/Plan_Nacional_de_Exceso_ de_Temperaturas_2015.pdf.

Mirón, I.J., Criado-Álvarez, J.J., Díaz, J., Linares, C., Mayoral, S., Montero, J.C., 2008. Time trends in minimum mortality temperatures in Castile-La Mancha (Central Spain): 1975-2003. Int. J. Biometeorol. 52, 291-299.

Pursiainen, V., Haapaniemi, T.H., Korpelainen, J.T., Sotaniemi, K.A., Myllylä, V.V., 2007. Sweating in Parkinsonian patients with wearing-off. Mov. Disord. 22 (6), 828-832.

Reese, J.P., Dams, J., Winter, Y., Balzer-Geldsetzer, M., Oertel, W.H., Dodel, R., 2012. Pharmacoeconomic considerations of treating patients with advanced Parkinson's disease. Expert. Opin. Pharmacother. 13 (7), 939-958. 
Ritz, B., PC, L., Hansen, J., CF, L., Ketzel, M., Sørensen, M., Raaschou-Nielsen, O., 2015. Traffic-related air pollution and parkinson's disease in Denmark: a case-control study. Environm Health Perspect. http://dx.doi.org/10.1289/ehp.1409313.

Rodríguez-Blázquez, C., Forjaz, M.J., Lizán, L., Paz, S., Martínez-Martín, P., 2015. Estimating the direct and indirect costs associated with Parkinson's disease. Expert Rev. Pharmacoecon. Outcomes Res. 15, 889-911.

Samet, J., Dominici, F., Zeger, S., Schwartz, J., Dockery, D., 2000. The National Morbidity, Mortality and Air Pollution study, Part I: Methods and Methodologic Issues. Report No. 94, Part I. Health Effects Institute, Boston.

Schestatsky, P., Valls-Solé, J., Ehlers, J.A., Rieder, C.R., Gomes, I., 2006. Hyperhidrosis in Parkinson's disease. Mov. Disord. 21 (10), 1744-1748.

Stöllberger, C., Finsterer, J., 2007. Did thirst-blockers like angiotensin-converting-enzyme inhibitors, sartans, serotonine-re-uptake-inhibitors, dopamine agonists/antagonists, or atypical neuroleptics contribute to the exorbitant number of fatalities during the French 2003 heat wave? Pharmacoepidemiol. Drug Saf. 16, 1252-1253.

Swinn, L., Schrag, A., Viswanathan, R., Bloem, B.R., Lees, A., Quinn, N., 2003. Sweating dysfunction in Parkinson's disease. Mov. Disord. 18 (12), 1459-1463.

Umemura, A., Oeda, T., Tomita, S., Hayashi, R., Kohsaka, M., Park, K., Sugiyama, H., Sawada, H., 2014. Delirium and high fever are associated with subacute motor deterioration in Parkinson disease: a nested case-control study. PLoS ONE 9 (6), e94944.

Wirdefeldt, K., Adami, H.O., Cole, P., Trichopoulos, D., Mandel, J., 2011. Epidemiology and etiology of Parkinson's disease: a review of the evidence. Eur. J. Epidemiol. 26 (Suppl. 1), 1-58.

Yamashita, S., Uchida, Y., Kojima, S., Sakaguchi, H., Kimura, E., Maeda, Y., Uchino, M., 2012 Heatstroke in patients with Parkinson's disease. Neurol. Sci. 33 (3), 685-687. 